\title{
THE INTERSECTING WORLDS OF SUSTAINABILITY AND CYBERSPACE: OLD OR/AND NEW BOUNDARIES
}

\author{
Stanley D. Brunn ${ }^{\mathrm{a}, \mathrm{b}}$ \\ ${ }^{a}$ Department of Geography, University of Kentucky, Lexington, KY USA 40506 \\ b Yunnan Normal University, 298 Yieryi Dajie, Kunming, P.R. China 650092 \\ brunn@uky.edu
}

KEY WORDS: boundaries; cyberspace; sustainability; environment

\begin{abstract}
:
The world is replete with boundaries at all scales, personal, community, disciplinary, national and global. Some of these are open and permeable; others are closed and difficult to cross. The fields, concepts and models associated with studying global sustainability call for an examination of both old boundaries and new boundaries, especially those that intersect different disciplines, scales and technologies. In this presentation I want to focus on new transdisciplinary boundaries that are essential for us to study sustainability at local and global levels and also cyberspace worlds where there is much fluidity, speed, networking that relate to issues of identity and territoriality. I discuss both what is similar to "old" or "traditional boundary thinking" and what is "new." I conclude by suggesting some challenges facing transitional boundary research and policy.
\end{abstract}

\section{INTRODUCTION}

Boundaries are part of life and living. They exist at all scales: personal, family, community, regional and global and also disciplinary. Boundaries can be fixed and formal or fluid; they can be temporary or permanent; they can be temporal, fixed; they can also be open and porous. Sometimes those boundaries are easily to delimit and define; other times they are fuzzy and fluid. What is important to remember that boundaries have always existed in human history, sometimes erased to provide inclusion and acceptance, other times as sources of conflict. Identity and territory or territory are but two ways we seek to provide meaning and order to the worlds around us, whether they be geographical or temporal, personal or global, disciplinary or interdisciplinary. Problems often arise when we seek ways to define something new or establish a boundary around some new group or subject matter. It is only natural that boundaries are sought to provide inclusion or even separateness. Crossing boundaries are part of the human experience, including those who write and study subject matter that is often difficult to define include in one particular "bounded category." This point we will observe often in this conference.

In this presentation, I discuss boundaries within, between and across disciplines, which for me is the conference's central focus The subjects related to "borderlands" and "global sustainability" provide many examples of intersecting worlds at all scales (local to global), disciplines and methodologies. Below I focus on the intersections between sustainability and cyberspace, which in my mind call for some new or creative ways of looking not only at these two subjects, but also at the intersections. In particular, I examine our "boundary thinking" before these words appeared in our lexicon, teaching/research and policy. Before proceeding, is is important to have some discussion of the terms "sustainable" and "sustainability" and what is "a geography of sustainability."

\section{DEFINING SUSTAINABILITY AND USES OF THE TERM}

Sustainability refers to something that is not completely used up or destroyed, but rather has features that can still be used. Frequently, the term refers to natural resources, such as forests or soils which are not used completely or exhausted, that is, they be replenished or made renewable for reuse. Various conservation methods have been applied through human history to preserve forests, water and agricultural lands for future use. The term sustainability has been adopted very widely in academic and policy circles to refer to the recycling of resources and industrial products and methods to conserve wisely natural resources (wind, water, land).

A central question arises for those interested in looking at the term sustainability in a knowledge-world and also the international arena. And that is, how can we obtain measure the use of this term. I suggest one fruitful direction is to explore the use of the term using the Google Search Engine. This information source provides hyperlinks or electronic sources or pieces of information about any subject we enter into the Search Engine "box." When we enter the word "sustainable," for example, in October 2013, we learn there are 193 million hyperlinks or sources of information in the Google Search Engine that contain that word in a title, a report, a table, on a map, etc. And there 102 million for the word "sustainability." These are the number of entries in the English Google Search Engine; there may be more or less in Chinese, Spanish, French, Arabic and Russian. One might think of other sources or databases that would also provide some quantifiable measure of "sustainable" and "sustainability." One might think of books in a library or articles in magazines or newspapers or conferences on these subjects, however, my view is that in an electronic information world, electronic bits or bytes of information represent probably the best sources to learn how much is "out there" or published any given subject.

A further inquiry into the electronic worlds of sustainability can be obtained by including the word "sustainable" alongside related terms we commonly associated with "sustainable." For example, one can enter into the Google Search Engine "sustainable + agriculture" or "sustainable + forestry" or 


\section{5 - 6 December 2013, Beijing, China}

"sustainable + development" or "sustainable + tourism." Examples of the volume of hyperlinks associated with different combinations are shown in Figure 1 and Table 1. This table shows the word is associated with planning, architecture, law, religion, politics, medicine, energy, recycling, transportation, the military and education. The table confirms a point that the term "sustainable" is not only multidisciplinary, but also interdisciplinary and transdisciplinary, not just with a handful of study, but a wide range of topics studied in the social, behavioral and policy and natural sciences.

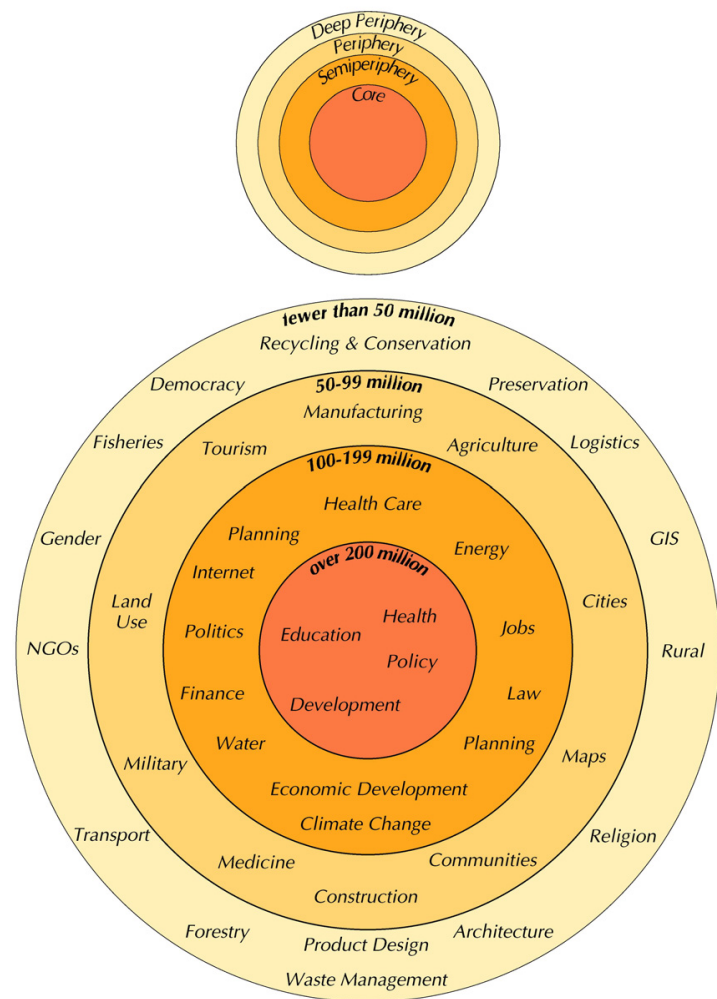

Figure1. Mapping Sustainability Hyperlinks from Google

\begin{tabular}{|c|c|}
\hline 200-300 million & Education; Policy; Health; Development \\
\hline 100-199 million & $\begin{array}{l}\text { Futures; Energy, Planning; Finances; } \\
\text { Politics; Health Care; Internet; Economic } \\
\text { Development; Water; Climate Change; } \\
\text { Living; Organizations; Law }\end{array}$ \\
\hline 50-99 million & $\begin{array}{l}\text { Investment; LandUse; Construction; Cities; } \\
\text { Military; Manufacturing; Medicine; } \\
\text { Agriculture; Maps; Communities; Tourism }\end{array}$ \\
\hline 25-49 million & $\begin{array}{lrr}\text { Design; Conservation; Product } & \text { Design; } \\
\text { Democracy; } \quad \text { Recycling; } & \text { Waste } \\
\text { Management; Rural; Literature; Transport }\end{array}$ \\
\hline 25 million & $\begin{array}{l}\text { Preservation; Mapping; Gender; Logistics; } \\
\text { Architecture; Towns; NGOs; Religion; } \\
\text { Forestry; Fisheries; GIS }\end{array}$ \\
\hline
\end{tabular}

Table 1. Entries in Google Search Engine about Sustainability

(Source: Accessed Google Search Engine; 2 October 2013)

Another perspective can be obtained by looking at professional journals with the word "sustainable" in the title. One would expect these journals to be both disciplinary and interdisciplinary in contributions, co-authors, editorial board members, boo reviewers and conceptual or theoretical frameworks. I identified more than fifty published in English

\begin{tabular}{|c|c|}
\hline General & $\begin{array}{l}\text { Environment, Development and } \\
\text { Sustainability; Journal of a Sustainable } \\
\text { Society; International Journal of Sustainability }\end{array}$ \\
\hline Development & 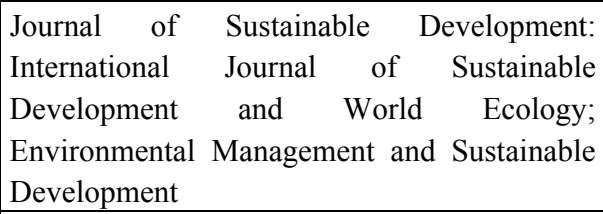 \\
\hline Agriculture & 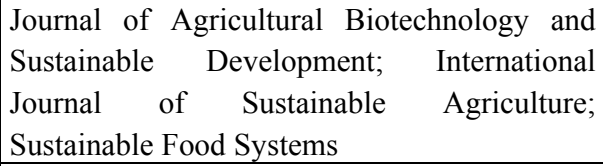 \\
\hline Education & $\begin{array}{l}\text { Journal of Education for Sustainable } \\
\text { Development: Journal of Sustainability in } \\
\text { Higher Education; Journal of Sustainable } \\
\text { Education }\end{array}$ \\
\hline Econ & $\begin{array}{l}\text { Journal of Economics and Sustainable } \\
\text { Development; Journal for a Global } \\
\text { Sustainable Information Economy }\end{array}$ \\
\hline Engine & $\begin{array}{l}\text { Journal of Sustainable Engineering; Journal of } \\
\text { Engineering for Sustainable Development }\end{array}$ \\
\hline & Sustainable Chemistry and Engineering \\
\hline & $\begin{array}{l}\text { Energy, Sustainability and Society; Journal of } \\
\text { Renewable and Sustainable Energy; } \\
\text { International Journal of Sustainable Human } \\
\text { Society }\end{array}$ \\
\hline & Sustainable Development Law and Policy \\
\hline & $\begin{array}{l}\text { International Journal of Sustainable Land Use } \\
\text { and Urban Planning; Sustainable } \\
\text { Development and Planning }\end{array}$ \\
\hline Architecture & $\begin{array}{l}\text { Journal of Creative and Sustainable } \\
\text { Architecture }\end{array}$ \\
\hline & le Construction \\
\hline Medicine & Journal of Ecologically Sustainable Medicine \\
\hline Transport & Journal of Logistics and Sustainable Transport \\
\hline $\begin{array}{l}\text { Manufacturin } \\
\mathrm{g}\end{array}$ & $\begin{array}{l}\text { Journal of Sustainable Manufacturing and } \\
\text { Renewable Energy }\end{array}$ \\
\hline Water & $\begin{array}{l}\text { International Journal of Sustainable Water and } \\
\text { Environmental Systems }\end{array}$ \\
\hline & Journal of Sustainable Forestry \\
\hline & Journal of Sustainable Tourism \\
\hline Regional & Journal of Sustainable Development in Africa \\
\hline
\end{tabular}

Figure2. Titles of Academic Journals about Sustainability

(Source: Google Search Engine, Accessed 2 October 2013.)

with the word "sustainable" in the title.. I am sure there are many more if one searched for journals published in German, French, Russian, Chinese, Arabic, Dutch, Portuguese and Japanese. Examples of journals I identified include the Journal of Ecologically Sustainable Medicine, the International Journal of Sustainability, Journal of Sustainable Tourism, Journal of Sustainable Development in Africa, Sustainable Construction, Sustainable Development and Planning and others (Table 2). This table reflects the diversity of disciplines and fields and subfields interested in sustainability; they include law, chemistry, agriculture, forestry, education, engineering, architecture, water, economies and also manufacturing and real estate. I would also expect that on close examination that most started in the 1970s and 1980s. Also I know there would many 


\section{5 - 6 December 2013, Beijing, China}

more articles about sustainable development with the words "environment" and "ecology" in their titles. There are many scholars in different disciplines and in many different countries writing about sustainability means who are already crossing formal traditional disciplinary boundaries for references, theories, models, conceptual frameworks and methodologies.

\section{TOWARDS A GLOBAL GEOGRAPHY OF SUSTAINABILITY}

The two questions I raise in this section are: (1) can one "map" sustainability at a global scale and (2) what measure would you use? To answer these questions, I use the Google Search Engine and enter the word "sustainable" with the nearly 200 countries on the world political map. For example, by entering "sustainable + Belgium" or "sustainable + Vietnam" or "sustainable + Nigeria," I obtain the number of paired hyperlinks, for each country. The number of hyperlinks refers to the number of electronic entries in the Search Engine about that country. One could compare the "hyperlink volume" with other countries in same region or on a world scale. If I looked at the subject matter for the first ten hyperlinks (which are most important), I would learn what topics are most important. The leading hyperlinks may be about a new development a sustainable development program, a community effort, a photoessay. a recent academic conference, a government or NGO report or a report. The contributors would have come from many different backgrounds, disciplines, and countries, again attesting to the interdisciplinary nature of the subject.

I consider the "volume" or number of hyperlinks as a measure of how important sustainable issues or topics and sustainability are in that country. If there are many of these electronic information sources, then sustainability are more important than if there were only a few. A small number of hyperlinks may be attributed to the fact that "sustainable" issues are not that important in the government, planning and education agendas. The number of references to sustainability ranged from China with 150 million hyperlinks to the Vatican City with 2.4 million. Figure 2 shows the global distribution of the term "sustainability" with the world's states (small Caribbean and Pacific Island states were not included because of their size). There were six countries with more than 100 million hyperlinks about "sustainability;" following China, they were the United States (146 million), Canada (137 million), India (135 million), Australia (121 million) and Japan (102 million). Other countries with very few hyperlinks were Nauru (4.29 million), Andorra (4.27 million), San Marino (4.26 million), St. Kitts and Nevis (2.5 million). All are ministates.

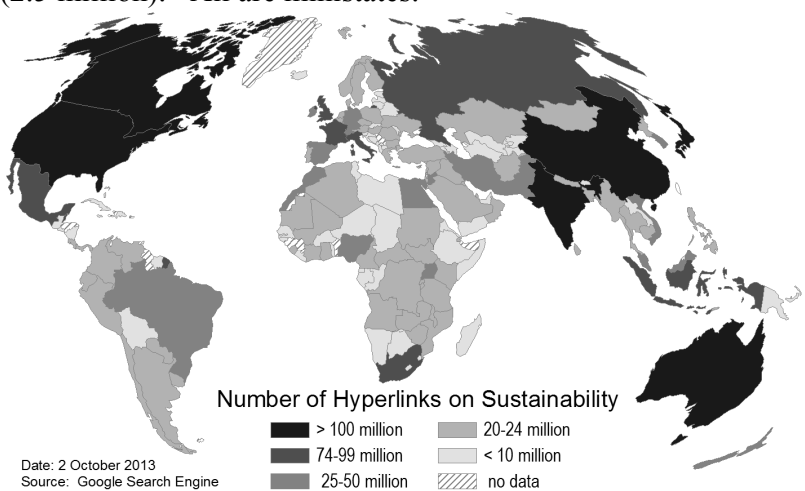

Figure 2. Frequency map of sustainability hyperlinks

There are some unexpected results. Belize, the ministate in Central America, and a former British colony, had the same number of "sustainable hyperlinks" (88 million) as France, this is because sustainable tourism is a major promotional feature of this ministate. South Africa was not far behind. Mexico, Italy and Indonesia had 60-70 million hyperlinks compared to 56 million for Russia and 51 million for the United Kingdom. There was often little regional homogeneity. For example, Germany, Iran, New Zealand, Pakistan and Ireland had 40-49 million and Nigeria, Sweden, South Korea and Jordan had between 30-39 million. Between 20-29 million were the Netherlands, Philippines, South Sudan and Haiti. Between 1019 million were Mali, Nepal, Paraguay, Tanzania, Myanmar and Luxembourg. Most of the countries with fewest "sustainable hyperlinks" were among the poorest on the planet. The sustainability map illustrates a key geographical component of global sustainability, viz., that geographical boundaries do indeed make a difference. There are clear differences often not only in bordering countries but also countries traditionally considered by geographers as being in the same region.

\section{EVOLUTION AND DEFINITION OF THE TERMS: SUSTAINABILITY AND CYBERSPACE}

The subject matter related to sustainability emerged from the ecology/environmental thinking and popular cultural movements in the late 1950s and early 1960s. If one was looking at studying sustainability, one would mostly likely have looked for subject matter and theories from the biological sciences and perhaps agricultural sciences. Specialists in these fields were trained and published research on topics about water resources, crop science, soil mechanics, conservation and preservation, plant and animal ecology. These scientists were often trained in specific subjects and were most familiar with models, theories and techniques in their own fields. Colleges and universities had specific departments offering degrees in these fields. In short, the knowledge that was produced for specialists was primarily disciplinary or defined by a specific way of looking at the world or at, what we call today, a "nature/society" world. Specialized journals and conferences were held for these disciplinary or narrowly-defined subfields. In a sense, one could define these worlds a as "operating in a series of parallel universes." Boundaries defined and often jealously protected what one studied and what one studied was distinctly separate from many other disciplines' thinking, even if there were commonalities. The term "environment" was mostly associated with the natural sciences.

Entering these "parallel universes" from the 1970s and 1980s and early 1990s and beyond were two major shifts that were underway in how we think about nature and society. First the word environment emerged as a concept in new disciplines and newly defined fields. Both ecology and environment were assuming more than a natural science focus. The social sciences and humanities began to look at issues about human use of the earth, care for the land, ethical issues regarding resource use, native and indigenous rights to land and resources, gender and politics and the environment. Sustainability, landscape preservation, climate change, political ecology, and biodiversity all became associated with the some "new" thinking about humans and the land, water, air, and resources. Entirely new fields were created in disciplines that previously had little or no "environmental" focus, such as political science, religious studies, urban studies and health policy and new transdisciplinary fields such as feminist ecology, green religion, environmental literature, global modeling, environmental law, public participation GIS, environmental philosophy and 


\section{5 - 6 December 2013, Beijing, China}

environmental chemistry. The intellectual landscape suddenly changed from a disciplinary to an interdisciplinary and transdisciplinary landscape where the natural and social sciences and humanities were intersecting and developing new models, theories and methodologies and techniques to study issues about resources, resource use, policy and conservation. There were also new interdisciplinary journals, interdisciplinary conferences and multidisciplinary funding sources. The intellectual and policy communities realized that the best way to study broad questions about the environment was by integrating and introducing subject matter and techniques from other fields. In short, boundaries that once were fixed, rigid and formal were now disappearing with junior and senior scholars willingly crossing boundaries about subject matter and also welcoming new perspectives in looking at issues about environmental use and misuse. Who would have thought twenty years ago that scholars studying religion, political science, literature, philosophy, chemistry and economics would have anything to say about environmental issues?

\section{CYBERSPACE AND THE ENVIRONMENT}

I consider the emergence of the study of the human environment and human/physical environmental interfaces one of the major transdisciplinary developments in the past twentyfive years. A second disciplinary evolution is associated with cyberspace or the virtual worlds of time and space. This subject matter area did not have an intellectual heritage that we observed in the case of studying the environment. As we noted, we had scientists studying plant and animal communities, soils, hydrology and mineral sciences; these also included geographers. When cyberworlds appeared on the intellectual horizons, there were initially associated with computer science and staffed by professionals from mechanical engineering, statistics, mathematics and physical and social scientists. These mathematical models and statistical testing were introduced into a wide variety of disciplines that heretofore had little research or teaching courses using numerical analyses. Developments in these statistical and later cyberworlds came with those trained in behavioral psychology, cartography/geography, the geosciences, architecture and graphics design. The next major developments in these disciplinary and then interdisciplinary subfields came with the introduction of the internet in the late 1980s and early 1990s. The internet changed the direction and scope of many disciplines because it introduced elements of speed, fluidity and networking, all encouraging junior and senior scholars to participate in the transdisciplinary and interdisciplinary worlds, including environmental studies.

Two examples illustrate the changing intellectual terrains associated with cyberspace. One was the introduction of Google Earth, which in itself promoted and instilled global thinking about many subjects that were almost unthinkable a decade earlier. Google Earth was used by professionals studying weather and climate, crop patterns, ocean navigation, land use and land cover, and also transportation networks. That this was a "visual" presentation about the environment made it a valuable and useful product for analysis and policy. The second visual contribution was the World Wide Web. This proved to be not only a source of visual information about a multitude of topics and issues, but a source of information on almost any subject imaginable. The WWW contains electronic data pieces (maps, texts, charts, etc.) about cities, land use, populations, tourist sites, and includes information provided by individuals, companies, nongovernmental organizations and governments.
The internet, Google, the WWW and GIS entered the scientific, educational and policy communities at a time when there was strong interest and acceptance of thinking about topics and problems beyond the traditional "boxes" or parallel universes that described the world of thinking a couple decades earlier. Specifically, visual foundations of Google, GIS and the WWW, meant that visual depiction of topics and presentation of topics was not only considered within the prevue of geography or anthropology, but for those in behavioral psychology, media studies, tourism, and also environmental studies and global change. It is probably safe to state that every field and subfield has benefitted from the internet, either as a source or resource for studying topics and for communicating with others with similar interests. And probably every field or subfield has scholars who study the internet and philosophy, literature, cultural change, local politics, religion, architecture and the environment.

In short, the internet, Google, GIS and the WWW have changed the way we think about subjects and subject matter, but they also represent boundary-crossing of subject matter and methodology. The impacts of these developments will change the way we think about problems or issues and also about how to solve problems. Disciplinary thinking as a "single or simple box" or knowledge is being replaced by professionals who cross, often with relative ease, into the intellectual territory of related fields. Students are being trained in methodologies and with techniques that are not discipline-specific, but rather cross boundaries with disciplines in the social sciences and earth sciences, the engineering sciences and humanities and earth sciences and humanities. Subfields such as digital humanities, visual history, cyberphilosophy, virtual religion, virtual environments, and virtual gaming attest to this point.

\section{CHALLENGES TO BOUNDARIES IN EMERGING WORLDS}

While the boundaries for those studying the environment and cyberspace and especially the intersections of these intellectual spheres of study have been reduced, I maintain there are still crucial boundary issues that need to be considered. Boundary issues have not disappeared, nor will they disappear in the near or distant future. Staying with the topic of this presentation, viz., sustainability and cyberspace in a globalized world, I can identify six "boundary" questions that will be of interest to those in the intellectual, community and policy communities.

1. How can one promote success stories about local sustainability to wider and even global audiences? The interests in sustainability, whether related to improved land use and land cover schemes or recycling resources or teaching sustainability, are global, but often barriers exist that are political, gender, and even religious. Those who have successful stories and experiences need to be the "gatekeepers" (distance learning workshops) to disseminate this information.

2. Can PPGIS (public participation GIS) be used at local levels to improve and increase knowledge about human/environmental problems? For those who study PPGIS, they often recognize the empowerment of marginal groups who are hindered by "boundaries" that may be based on religious tradition, government and corporate bureaucracies.

3. Can the growing use of social media, especially in the Global South, be used to teach sound and effective practices about sustainability in agriculture, water resources, land use cover, and energy use and be disseminated rapidly, inexpensively, and easily? The wireless worlds, which also offer many opportunities for human progress, are still beset by 


\section{5-6 December 2013, Beijing, China}

boundaries and barriers related to income, class, and government structure.

4. What new ways or kinds of communication might be developed to share knowledge from the specialists in universities or laboratories or government offices with locals? Can one develop successful "one to many" models of communication? Technology, linguistic, gender and class barriers are among the boundaries that still need to be crossed.

5. What can the Global North learn from the Global South about sustainability? A unidirectional (Global North to Global South) model is often seen as the preferred model to learn about improved methods of conserving resources or community empowerment strategies or the successful diffusion of new practices. However, I submit the North has much to learn from the South about sustainability as related to resource use, conservation and shared governance.

6. In short, how does one develop and promote effectively the concept of "a global sustainable world?" Visually (Google, WWW, social media, tv, maps, etc.) is one way. And we know that economic, gender, political and class barriers still exist regarding access of visual information to improve the human condition.

\section{SUMMARY AND CONCLUSION}

In this presentation, my objectives have been three fold. First, I wanted us to think about the "bounded and boundary worlds" in which many of us grew up and which, for many still exist. Second, I wanted us to think how studying the environment has changed in focus and approach in the past couple decades with new and renewed transdisciplinary and transboundary worlds. The third objective was to introduce the worlds of cyberspace and how they have changed and are changing the way we look at environmental and also other topics. And finally, I wanted us to realize that in spite of all the boundary crossing and blurredness that exists in the knowledge world, there are still boundaries and barriers that exist, even in environmental and global thinking. These are political, but also gender, religious, class, language and I would maintain, also disciplinary to some extent. These boundaries may be harder to erase than disciplinary boundaries, but if we seek, as I believe we all do, to practice sustainability at personal, local and global worlds, we have to be become "sustainable scholars across boundaries" in the worlds we live, work, worship, have fun and govern. 